\title{
Yield Loss Potential of Phaeosphaeria Leaf Spot of Maize Caused by Phaeosphaeria maydis in the United States
}

\author{
M. L. Carson, United States Department of Agriculture-Agricultural Research Service (USDA-ARS), Cereal Dis- \\ ease Laboratory, St. Paul, MN 55108
}

\begin{abstract}
Carson, M. L. 2005. Yield loss potential of Phaeosphaeria leaf spot of maize caused by Phaeosphaeria maydis in the United States. Plant Dis. 89:986-988.

The ability of Phaeosphaeria leaf spot (PLS) to reduce yields of maize was evaluated over two winter growing seasons in southern Florida. Nine commercial maize hybrids, varying in reaction to PLS, were planted in a split-plot design with hybrids as whole plots and inoculated versus uninoculated treatments as subplots. The most susceptible hybrid, Pioneer brand 3489, sustained a significant reduction in grain yield (11 to $13 \%$ ) and 400-kernel weight (5 to $10 \%)$ in the trials. Regression analyses indicated that grain yields and 400-kernel weights were reduced 0.23 and $0.16 \%$, respectively, for each percent increase in PLS severity at the mid-dent stage. Because most U.S. maize hybrids are resistant, and PLS develops late in the grain-filling period, its potential to cause substantial losses in the United States appears limited at this time.
\end{abstract}

Phaeosphaeria leaf spot (PLS) is caused by the ascomycete Phaeosphaeria maydis (Henn.) Rane, Payak, \& Renfro (anamorph = Phoma maydis, synonym = Leptosphaeria zea-maydis Saccas; Metasphaeria maydis (Henn.) Höhnel), and is a potentially serious foliar disease of maize that is widely distributed in Central and South America, Asia, and Africa $(2,4,9)$. PLS is most prevalent in areas of high rainfall and moderate temperatures, such as occur at higher elevations in the tropics. It is becoming an increasingly important disease of maize in South Africa and Brazil $(6,8)$. PLS has occurred regularly in southern Florida winter maize breeding nurseries since at least the 1990, but has yet to appear in the rest of the continental United States (4). The ability of PLS to cause damage to maize in other areas of the world makes the introduction of the disease to the United States a potential concern. Initial observations and later replicated inoculated trials of PLS in southern Florida nurseries indicated that the inbred line B73 and its derivatives were particularly susceptible $(2,4)$. Not all B73-derived lines were as susceptible as B73, and some unrelated lines also were found to be quite

Corresponding author: M. L. Carson

E-mail: mcarson@umn.udu

Former address: USDA-ARS, Plant Science Research, Raleigh, NC 27695.

Accepted for publication 5 May 2005.

DOI: 10.1094/PD-89-0986

This article is in the public domain and not copyrightable. It may be freely reprinted with customary crediting of the source. The American Phytopathological Society, 2005. susceptible to PLS (2). Only a few commercial hybrids were as severely infected as the susceptible hybrid check, indicating that U.S. maize production is not particularly vulnerable to damage from PLS. The susceptibility of several inbred lines widely used as female (seed) parents of commercial hybrids makes this disease a potential concern to the seed industry should it become established in areas of hybrid seed production (2).

Based on generation mean analysis of segregating populations derived from the cross B73 $\times$ Mo17, resistance to PLS in the inbred line Mo17 appears to be incom- pletely dominant, highly heritable, and controlled by three to four genes, (3). Five quantitative trait loci (QTL) on four different chromosomes (chromosomes 1, 4, 7, and 8) were found to control PLS resistance in Mo17 based on mapping in a set of random, recombinant inbred (RI) lines derived from the cross B73 $\times$ Mo17 (5). In addition, the additive-additive interaction between two of these QTL was significant.

The objectives of this study were to determine if PLS can significantly reduce maize grain yields and the relationship, if any, between PLS severity and grain yield losses.

\section{MATERIALS AND METHODS}

Germ plasm. Nine commercial hybrids were selected to represent a range in levels of resistance to PLS based on previous evaluations (2). The seed was provided courtesy of Pioneer Hi-Bred International (Johnston, IA) and Dekalb Genetics (Dekalb, IL). Eight hybrids (Pioneer brand hybrids 3217, 3279, 3293, 3313, 3352, 3394,3437 , and 3489) were evaluated in the winter of 1999-2000. In the winter of 2001-02, Dekalb hybrid DK683 was substituted for Pioneer brand hybrid 3293, which was no longer available. Both hybrids had similar high levels of resistance to PLS.

Table 1. Reductions in grain yield, 400-kernel weight, and percent Phaeosphaeria leaf spot (PLS) disease severity in plots inoculated with Phaeosphaeria maydis versus uninoculated plots in two winter growing seasons in Homestead, $\mathrm{FL}^{\mathrm{z}}$

\begin{tabular}{lccc}
\hline Season, hybrid & $\begin{array}{c}\text { Yield loss in } \\
\text { Mg ha }^{-1}(\boldsymbol{\%})\end{array}$ & $\begin{array}{c}\text { Kernel wt. in } \\
\text { grams (\%) }\end{array}$ & $\begin{array}{c}\text { Percent } \\
\text { PLS severity }\end{array}$ \\
\hline 1999-2000 & & & \\
Pioneer Hybrid 3217 & $-0.22(-3.8)$ & $2.3(1.7)$ & $1.0 \mathrm{~d}$ \\
Pioneer Hybrid 3279 & $0.27(4.0)$ & $15.8 * *(12.3)$ & $17.0 \mathrm{~b}$ \\
Pioneer Hybrid 3293 & $0.46(7.1)$ & $5.0(3.6)$ & $0.02 \mathrm{~d}$ \\
Pioneer Hybrid 3313 & $0.20(2.6)$ & $-6.1(-5.0)$ & $5.5 \mathrm{c}$ \\
Pioneer Hybrid 3352 & $-0.03(-0.4)$ & $-9.0(-6.5)$ & $0.2 \mathrm{~d}$ \\
Pioneer Hybrid 3394 & $-0.05(-0.7)$ & $-3.3(-2.3)$ & $6.0 \mathrm{c}$ \\
Pioneer Hybrid 3437 & $-0.05(-0.7)$ & $-2.7(-2.0)$ & $4.8 \mathrm{c}$ \\
Pioneer Hybrid 3489 & $0.70 *(11.1)$ & $10.5 *(9.0)$ & $42.5 \mathrm{a}$ \\
Dekalb Hybrid 683 & $\ldots$ & $\ldots$ & $\ldots .5 \mathrm{~d}$ \\
2001-02 & $\ldots .32(-3.0)$ & $-2.0(-1.0)$ & $23.3 \mathrm{~b}$ \\
Pioneer Hybrid 3217 & $-0.36(2.8)$ & $4.7(2.8)$ & $\ldots$ \\
Pioneer Hybrid 3279 & 0.26 & $\ldots$ & $1.7 \mathrm{~d}$ \\
Pioneer Hybrid 3293 & $\ldots$ & $-1.8(-1.0)$ & $0.0 \mathrm{~d}$ \\
Pioneer Hybrid 3313 & $-0.28(-2.8)$ & $-1.7(-1.0)$ & $4.7 \mathrm{c}$ \\
Pioneer Hybrid 3352 & $-0.12(-1.3)$ & $-6.1(-3.1)$ & $2.2 \mathrm{c}, \mathrm{d}$ \\
Pioneer Hybrid 3394 & $-0.56(-4.8)$ & $-5.1(-2.7)$ & $64.2 \mathrm{a}$ \\
Pioneer Hybrid 3437 & $0.00(0)$ & $8.3 *(4.8)$ & $0.5 \mathrm{~d}$ \\
Pioneer Hybrid 3489 & $1.13 *(13.4)$ & $1.6(1.0)$ & \\
Dekalb Hybrid 683 & $0.30(3.1)$ & & \\
\hline
\end{tabular}

${ }^{\mathrm{z}}$ Mean PLS severities within each growing season followed by the same letter are not significantly different based on the FLSD statistic $(P \leq 0.05)$. * and ** indicate yield loss or reduction in kernel weight significantly different from zero at the $P=0.05$ or $P=0.01$ level of probability, respectively. 
Experimental design. Hybrids were planted in early November 1999 and midSeptember 2001 on a private farm near Homestead, FL. An identical experiment was planted in November 2000 but was abandoned due to lack of disease development in inoculated plots. Each experiment consisted of a split-plot design with whole plots (hybrids) arranged in a randomized complete block design with six replications. Split plots consisted of inoculated or uninoculated treatments. Experimental units consisted of single rows, $4 \mathrm{~m}$ long and $0.9 \mathrm{~m}$ apart, with 20 seed planted per plot. Plots were not thinned. Plots were inoculated at the 8- to 10-leaf stage by placing approximately 20 to 30 kernels of sorghum grain cultures of $P$. maydis into the leaf whorls. Inoculum was prepared by soaking sorghum seed overnight in tap water, draining off the excess water, placing the seed in 1-liter flasks, and autoclaving for $1 \mathrm{~h}$. After flasks had cooled, they were inoculated with an aqueous suspension of 3-week-old corn leaf agar (CLA; 11) cultures of a Florida isolate (FL-1) of $P$. maydis . Stock cultures were maintained as conidial suspensions in $15 \%$ glycerol at $-80^{\circ} \mathrm{C}$. Sorghum grain cultures were stored at $4^{\circ} \mathrm{C}$ until used. Plots were rated at the mid-dent growth stage $(\mathrm{R} 5.5 ; 10)$ by visually estimating the percent leaf area spotted in each plot. Plots were harvested by hand after physiological maturity and total grain weight, moisture percentage, and the weight of a 400-kernel sample from each plot were recorded. Plot grain yields were corrected for stands and converted to megagrams per hectare at $15.5 \%$ grain moisture basis. Data were analyzed using analysis of variance, and the least significant difference $(P \leq 0.05)$ statistic, using the correct error term in the split-plot analysis, was used to compare mean grain yields and 400-kernel weights of inoculated versus noninoculated plots within each hybrid and PLS severity ratings of inoculated plots of each hybrid. Linear regression was used to determine the relationship between percent losses in grain yield and kernel weight, and PLS severities.

\section{RESULTS AND DISCUSSION}

Substantial PLS had developed on inoculated plots of the susceptible hybrid Pioneer brand 3489 during the grain-filling period in both winter growing seasons. Only low amounts of PLS were present in uninoculated plots (mean PLS rating < $1 \%$; data not shown) in the 1999-2000 season. In the 2001-02 season, there was substantial PLS development in uninoculated plots of the more susceptible hybrids. Uninoculated plots of Pioneer brand hybrid 3489 had reached a $17 \%$ severity at the time of disease rating. The ability of PLS to reduce yield was apparent only when yields of inoculated and uninoculated plots of the most susceptible hybrid, Pioneer brand hybrid 3489, were com- pared. It was the only hybrid to sustain a statistically significant loss in grain yield and 400-kernel weight in both growing seasons (Table 1). The relatively low loss (10 to $13 \%)$ is consistent with that expected from the delay in development of PLS until after anthesis. Kernel weight of the next most susceptible hybrid, Pioneer brand hybrid 3279, was significantly reduced in the 1999-2000 season, but grain yield was not significantly affected.

When percent grain yield loss and 400kernel weight were regressed against PLS severities, 65 and $33 \%$ of the variation,

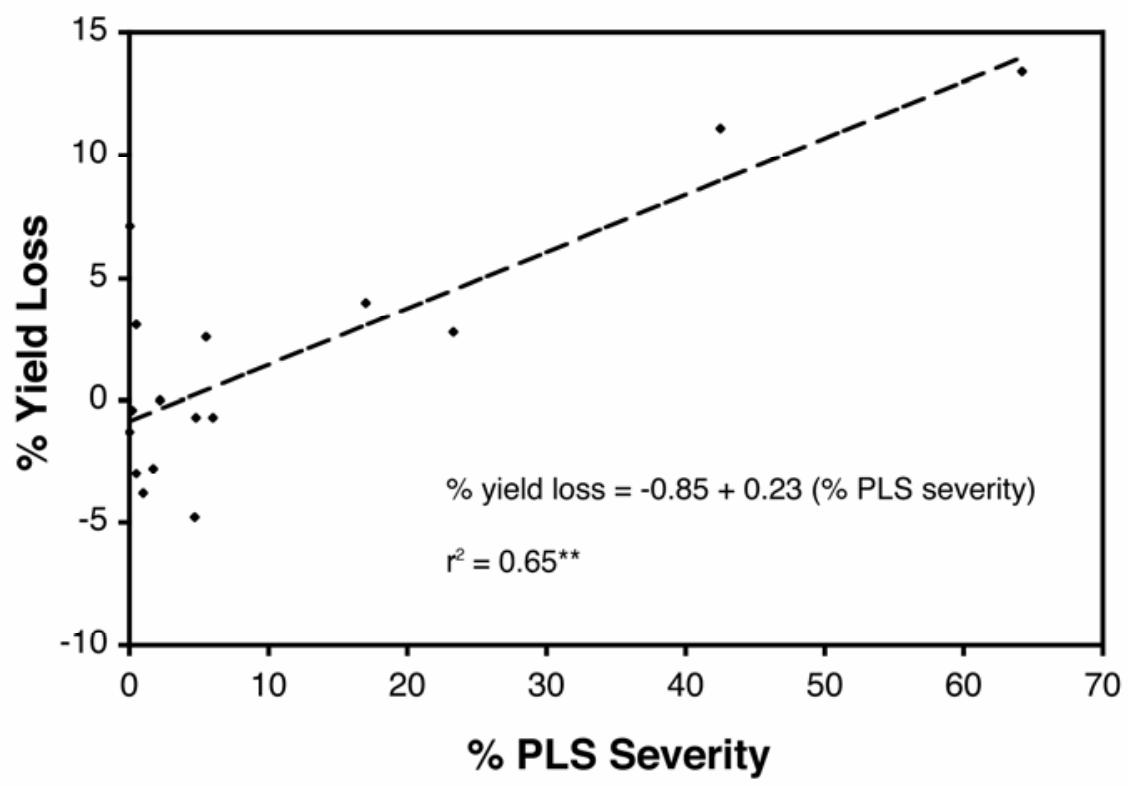

Fig. 1. Relationship between percent severity of Phaeosphaeria leaf spot (PLS) and percent loss when grain yields of plots inoculated with Phaeosphaeria maydis are compared with uninoculated plots. Data points are the means of six replications in each of two winter growing seasons in southern Florida.

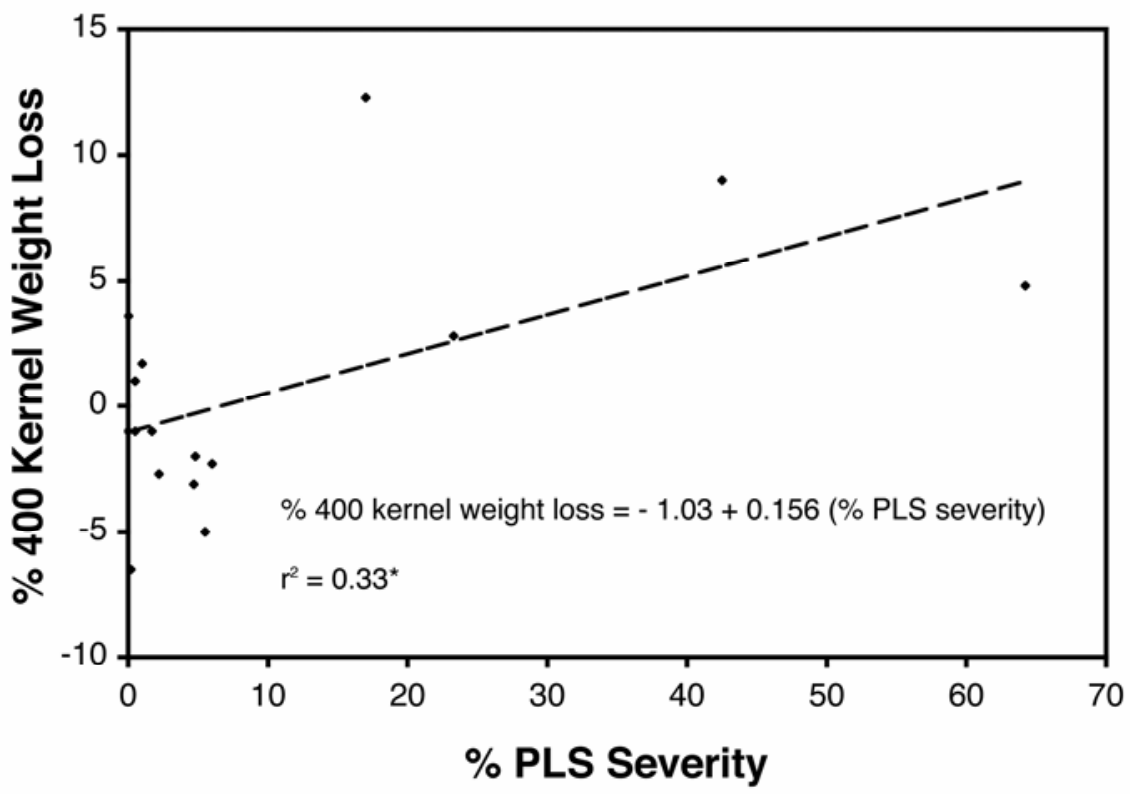

Fig. 2. Relationship between percent severity of Phaeosphaeria leaf spot (PLS) and percent loss when 400-kernel weights of plots inoculated with Phaeosphaeria maydis are compared with uninoculated plots. Data points are the means of six replications in each of two winter growing seasons in southern Florida. 
to eight-leaf stage (V6 to V8; 10), indicating that this disease has a long latent period and has limited potential for secondary disease development. Because it develops late in the grain-filling period, PLS would not be expected to be as damaging as other foliar diseases that may appear before anthesis.

The potential of PLS to cause substantial yield losses to the U.S. maize crop in the near future appears to be limited. Thus far, the disease has been confined to southern Florida in the United States and there is no indication of further spread. Furthermore, most of the current germ plasm base of U.S. maize hybrids is highly resistant to PLS (2). This study demonstrates that only the most susceptible U.S. hybrids, artificially inoculated and under conditions favorable for disease, sustain a significant grain yield loss to PLS. However, it should be kept in mind that little is known about the epidemiology of this disease or its potential to spread into and become established in more temperate regions of the United States, including the Midwestern maize belt. Basic information on dispersal, overwintering, and survival, and temperature, light, and moisture requirements for this pathogen is lacking. It also is possible that future changes in the genetic base of U.S. maize hybrids could result in an inadvertent shift toward increased susceptibility and increased vulnerability to PLS. The winter growing season in southern Florida is not representative of growing conditions occurring in the summer in the central United States, and estimates of potential yield loss may not be applicable to that environment.

\section{LITERATURE CITED}

1. Byrnes, K. J., Pataky, J. K., and White, D. G. 1989. Relationships between yield of three maize hybrids and severity of southern leaf blight caused by race $\mathrm{O}$ of Bipolaris maydis. Plant Dis. 73:834-840.

2. Carson, M. L., 1999. Vulnerability of U.S. maize germplasm to Phaeosphaeria leaf spot. Plant Dis. 83:462-464.

3. Carson, M. L., 2001. Inheritance of resistance to Phaeosphaeria leaf spot of maize. Plant Dis. 85:798-800.

4. Carson, M. L., Goodman, M. M., and Glawe,
D. A. 1991. Phaeosphaeria leafspot of maize in Florida. Plant Dis. 75:968.

5. Carson, M. L., Stuber, C. W., and Senior, M. L. 2005. Quantitative Trait Loci Conditioning Resistance to Phaeosphaeria Leaf Spot of Maize Caused by Phaeosphaeria maydis. Plant Dis. 89:571-574.

6. Casela, C. R. 1998. The Phaeosphaeria leaf spot. Pages 15-17 in: Diagnosing Maize Diseases in Latin America. C. R. Casela, R. Renfro, and A. Krattiger, eds. ISAA/EMBRAPA, Ithaca, NY.

7. Fisher, D. A., Hooker, A. L., Lim, S. M., and Smith, D. R. 1976. Leaf infection and yield loss caused by four Helminthosporium leaf diseases of corn. Phytopathology 66:942-944.

8. Flett, B. C., Bensch, M. J., Smit, E., and Fourie, H. 1996. A Field Guide for Identification of Maize Diseases in South Africa. ARC-LNR, Potchefstroom, South Africa

9. Rane, M. S., Payak, M. M., and Renfro, B. L. 1966. A Phaeosphaeria leaf spot of maize. Indian Phytopathol. Soc. Bull. 3:8-10.

10. Ritchie, S. W., Hanway, J. J., and Benson, G. O. 1993. How a corn plant develops. Iowa State Univ. Spec. Rep. No. 48

11. Trainor, M. J., and Martinson, C. A. 1978. Nutrition during spore production and the inoculum potential of Helminthosporium maydis race T. Phytopathology 68:1049-1053. 